\title{
Using the location-allocation P-median model for optimising locations for health care centres in the city of Jeddah City, Saudi Arabia
}

\author{
Abdulkader Murad, ${ }^{1}$ Fazlay Faruque, ${ }^{2}$ Ammar Naji, ${ }^{1}$ Alok Tiwari ${ }^{1}$ \\ ${ }^{1}$ Department of Urban and Regional Planning, Faculty of Architecture and Planning, King Abdulaziz \\ University, Saudi Arabia; ${ }^{2}$ Department of Preventive Medicine, University of Mississippi Medical Center, \\ Jackson, MS, USA
}

\begin{abstract}
Considering spatial accessibility of health services is a critical part in the planning and management of health services. There is evidence that poor geographical locations can obstruct prompt basic health care services to some population sections. We developed a location-allocation P-median model for health centres after analysing their sites, demand location of health services and the road network in Jeddah, Saudi Arabia. This model attempts to optimize health care services network and to put forward location recommendations to maximise service coverage. Our model is shown to be useful as it provides a robust evidence base to urban planners and policymakers responsible for making spatial decisions for the development of the health sector. Besides, it follows the paradigm of new urbanism that encourages decentralisation of essential facilities including basic healthcare in cities, where emphasis is on offering all basic services within walkable distances of $15 \mathrm{~min}$. or less.
\end{abstract}

\footnotetext{
Correspondence: Abdulkader Murad, Department of Urban and Regional Planning, Faculty of Architecture and Planning, King Abdulaziz University, Saudi Arabia.

E-mail: amurad@kau.edu.sa
}

Key words: Geographical information system; health centres; health demand; location-allocation; Jeddah; Saudi Arabia.

Acknowledgements: this project was funded by the Deanship of Scientific Research (DSR), King Abduaziz University, Jeddah, Saudi Arabia, under Grant no. KEP-8-137-41. The authors, therefore, acknowledge with thanks DSR technical and financial support.

Received for publication: 27 March 2021

Revision received: 15 May 2021

Accepted for publication: 17 May 2021

(C) Copyright: the Author(s), 2021

Licensee PAGEPress, Italy

Geospatial Health 2021; 16:1002

doi:10.4081/gh.2021.1002

This article is distributed under the terms of the Creative Commons Attribution Noncommercial License (CC BY-NC 4.0) which permits any noncommercial use, distribution, and reproduction in any medium, provided the original author(s) and source are credited.

\section{Introduction}

Globally, the Sustainable Development Goals (SDG), approved by the member states of the United Nations, stress the accessibility of good quality health services for all by 2030, without monetary distress being a limiting factor (Chotchoungchatchai et al., 2020). Indeed, prioritizing spatial accessibility of health services is a vital part in the planning and management of people's health conditions (Macharia et al., 2017). The distribution of health services is always important and when resources are limited, evaluation of their spatial variability becomes critical (Apparicio et al., 2017). There are several ways to measure spatial accessibility of health facilities, including the number of health centres available for a certain population, the estimated ratio of the population within a stipulated distance and the estimated ratio within a specified travel time from it (Guagliardo, 2004).

Analysis on spatial accessibility or variability of health services of any given area requires georeferenced distribution of data on population and locations of healthcare resources. Accessibility of a service can be improved if set up at the optimal location. In this context, location-allocation models (Rahman and Smith, 2000) have proved useful to find out the optimal location for the service provision within a city when the geographical distribution of the demand for a particular service is known. In general, demand is denoted in terms of consumers (people) who need that service. The P-median model is one of the efficient location-allocation models used to find out the optimum location for a service facility (Tomintz et al., 2015).

Some studies have successfully explored the utility of location-allocation models based on geographical information systems (GIS) in service provision (Ríos-Mercado et al., 2021), under which primarily median locations for the first centroids are determined (the location phase) and then the weights are assigned to centroids (the allocation phase). This type of models is used in optimising services, rendering of which depends upon geographical distances or on the time taken to cover these distances. In case of health centre accessibility, P-median is one of commonly used analytic tools for location-allocation models, in which points of demands are eventually allocated to the nearest supply facility (Jia et al., 2014). In fact, optimum location of health centres becomes more important in case of medical emergency at the time when the response time is critical (Dzator and Dzator, 2013). Researchers have been using P-median tools to locate and allocate emergency healthcare facilities in metropolitan cities, such as Belfast (McAleer and Naqvi, 1994), New York (Carson and Batta, 1990), Barcelona (Serra and Marianov, 1998) and Perth (Dzator and Dzator, 2013). P-median location allocation model might also be beneficial in optimising the location of both emergency health services, and basic health care services. In this study we deployed Pmedian for the health centre where the emergency medical ser- 
vices are available round the clock. Saudi Arabia has witnessed an unprecedented expansion in health facilities during the past seven decades. In 1949, only 100 beds and 111 doctors were providing health services for the entire Kingdom's 3-million large population (Papanikalaou, 1950), while the number reached 72,981 beds and 89,675 doctors in 2020 for a population of 34.8 million (Rahman and Al-Borie, 2020). In other words, only 0.21 beds were available for every 10,000 population in 1949 , while it had become 2.2 beds per 10,000 people in 2020. Additionally, the life expectancy in the Kingdom increased from 66 to 72 years only in the last three decades (Ministry of Health, 2020). Due to this expansion, the healthcare system in Saudi Arabia, according to the World Health Organisation (WHO), now ranks as 26 among 191 countries (WHO, 2000). However, even after this large-scale expansion, many studies report geographical variability in healthcare facilities. Areas with less geographic access to healthcare still exists for certain populations within the city boundaries (Murad, 2005; Khashoggi and Murad, 2020). To reduce this inequity, spatial analysis can help identifying the problems and suggest solutions (Salehi and Ahmadian, 2017; Kim et al., 2018; Murad, 2018; Wang, 2020).

The 15-min. city concept, i.e. access to all basic services within a walkable distance of $15 \mathrm{~min}$. or less, is on the rise in global cities (Euklidiadas, 2020; Vansynghel, 2020). This means that urban neighbourhoods should be planned so that all basic services and amenities (including healthcare) are decentralised and thus easily accessible by foot (Moreno et al., 2021; Smith 2021). This work presented here proposes a model for optimising health centre location in Jeddah, Saudi Arabia offering services to the majority of the population within 15-min. proximity using the P-median location allocation model.

\section{Materials and methods}

We structured the approach into five parts, each of which includes general knowledge and perspective on the history and application of GIS in the healthcare field. Section 2 discusses case studies and data points used to establish the locations of health care centres in the city of Jeddah and explains the process of implementation using ArcGIS (ESRI, Redlands, CA, USA). The results of the plotting of spatial data and location-allocation modelling are described in section 3, while sections 4 and 5 provide discussion, closing comments and suggestions for future work.

\section{Study area (City of Jeddah)}

The city of Jeddah, the heart of Jeddah Province, is $75 \mathrm{~km}$ from Makkah, $320 \mathrm{~km}$ from Madinah and about $850 \mathrm{~km}$ from the capital Riyadh. Its geographical location is important because it links Madinah with the city of Makkah providing the basic needs of the cities of Makkah and Madinah via the Jeddah Islamic Port and King Abdulaziz International Airport (Naji, 2020). The population of the city of Jeddah is distributed between various districts of varying population density. The Al-Safa, Al-Jami'a and Al-
Rabwah districts are the most populated. It also means that these districts have relatively higher number of demand points for health services. There is around $1765 \mathrm{~km}^{2}$ of urban boundary within the city that in 2017 had an estimated population of 3.43 million (General Authority of Statistics, 2018) Based on the 2019 census, the Jeddah metropolitan area has 61 primary care centres (PCCs) served by 691 doctors and 918 nurses, which gives a ratio of 1.94 centres per 100,000 people, now considered the lowest in the Kingdom (General Authority of Statistics, 2019). The city is highly car-dependent, with a negligible mode share of public transit among other transportation possibilities (Aljoufie and Tiwari, 2020, 2021).

\section{Data sources}

In any location allocation model, the location of facilities, the set of demand points, and the supply networks by which facilities fulfil the needs of the demand points are essential. Accordingly, for our model three primary maps were used. Data on health centre locations (the facilities) in Jeddah, and their respective capacities was obtained from the Ministry of Health office in Jeddah for the year 2020. Data on the population distribution (the demand points for possible health service) were collected from Jeddah Municipality for the year 2018. Road network data were acquired from Jeddah Municipality for the year 2020 as this reflects the supply network needed to fulfil the presumed health centre demand (Table 1). Demand points were created by converting population district polygons to point features

Next, a GIS database was built using the primary maps of the road network, population distribution, and the data on health centres. Several tools were used to construct the proper geo-database, including screen digitizing (heads-up) and a table of geocode addresses. Also required for this process was a table storing the addresses to be geocoded and a composite address locator. The application compares the addresses against the address locator and saves the output for each input record in the new point function class. The ArcGIS 'Smooth Polygon tool' was used to enhance aesthetic and cartographic consistency by smoothing sharp angles of polygon contours. All the data used in this study were crosschecked for geospatial accuracy, including: i) positional accuracy (absolute accuracy, relative accuracy and positional accuracy of the data in the grid); ii) thematic accuracy (correction of classification, degree of correction of quantitative attributes and accuracy of quantitative attributes); iii) temporal accuracy (accuracy of temporal measure, temporal consistency and temporal validity); iv) completeness (commissions and omissions); v) logical consistency (conceptual consistency, domain consistency, format consistency and topological consistency); and vi) usability. These requirements were introduced to satisfy acceptable quality parameters for the mapping criteria and the data were then used to optimize the health centre modelling process.

\section{Plotting the spatial data}

Automated map creation does not make use of the maximum potential provided by GIS for data plotting objectives. Currently, the most commonly used GIS plotting and mapping techniques in

Table 1. Source and use of data in the study.

\begin{tabular}{lll} 
Data & Source & Use \\
Location and capacity of health centres & Ministry of Health, Jeddah (2020) & To determine location of available facilities \\
Population distribution & Jeddah Municipality (2018) & To know the demand points of the service users \\
\hline Road network & Jeddah Municipality (2020) & To elucidate service network \\
\hline
\end{tabular}


the health care research sector include dot maps, diagram maps, choropleth maps, probability maps and flow maps (Kistemann and Queste, 2016). There are several ways to provide GIS functions focused on different public health data sources, including geocoding, data source aggregation and cluster identification. Mapping health data is generally accomplished by dot maps, choropleth maps and isopleth (or gradient) maps. Choropleth maps offer a simple way to present how a measurement differs, or to display the degree of heterogeneity within a field across a geographic area. In addition to choropleth maps, health data can be plotted as a graduated-symbol map, where symbols differ in size depending on the value of the attribute they represent, a technique used by the application described in this paper to classify health care centres based on the attributes of all centres. ArcGIS graduated symbols were used to illustrate a quantitative distinction between mapped features by changing the symbol scale. To represent the spectrum, health centre data were divided into ranges each assigned a symbol scale. The map of graduated symbols denoted numerical values, where larger symbols represent larger values. This type of map makes it easy for users to discern between low and high values, to see variations and to make comparisons.

\section{Classification}

The first step in classifying populations living near health centres is to define how far patients need to travel to access care. This objective falls under health care accessibility in the health care literature. Access is a multidimensional term, which is defined as the right to use health services when and where required and describes the interaction between the characteristics of service demands and the characteristics of service delivery mechanisms (Photis 2016). There are five important dimensions of access:

- Availability, defined as supply of services in relation to needs, i.e. are capacity and types of services adequate to meet the health care needs?

- Accessibility that is delineated by geographical barriers, including distance, transportation, travel time and cost. It highlights the geographical location of services in relation to the population's needs.

- Accommodation, defined as the degree at which services are organized to meet clients' needs, including hours of operation, application procedures and waiting times.

- Affordability that refers to the price of services in relation to people's ability to pay. Income levels and insurance coverage are critical aspects of this dimension.

- Acceptability that describes clients' views of health services and how service providers interact with them. It encompasses barriers linked to gender, culture, ethnicity and sexual orientation affecting the clients'willingness to use health services and the sense of comfort and satisfaction in receiving services (Elmes 2004; van Gaans, Hugo, and Tonkin 2016).

There are several common methods for the identification of a single attribute's spatial properties, including distribution (e.g., median, quartile, interquartile) and box plot. A variety of classification methods have been developed (Maheshwaran and Haining 2004), which include heuristic interchange; separated class; natural breaks; equal interval; and quintiles. The natural breaks method was selected as classification method for health centres in the city of Jeddah in this paper.

\section{Location-allocation modelling}

This study used the P-median tool of location-allocation model to optimize public health facilities in Jeddah (Lefebvre and Chapelet 2005). This kind of modelling is used in the context of existing available health care facilities and underlying demographic demand to determine the best places for new services, e.g., a new site for a maternity centre. Mathematical programming techniques are used for location-allocation modelling, where the programming can be defined as a collection of computational methods for solving optimization problems. This kind of models have been used in health care decision-making to determine the best place for a new facility, ensure that resource locations are sufficient to satisfy the needs of the network and to lay out the improved paths to health facilities in communities (Li et al., 2015). Several other situations have also been reviewed in which optimization models may be used to enhance connectivity or improve operations across the network (Luo et al., 2017; Wang, 2012). Changes, including the addition of restrictions, the use of various objective function values or separation of decision variables by form are possible with optimization modelling (Wang, 2012). There are a variety of standard location-allocation problems: The P-median problem minimizes the weighted distance between customers and providers; the location-covering problem (LCP) minimizes the number of services needed to cover all demands and the maximal location-covering problem (MCLP) maximizes demand within the optimal distance or time period by locating a specified number of services (Li et al., 2015).

Minimize weighted impedance, or P-median modelling available by ArcGIS software, was used in our application to identify a certain number of health care facilities between a range of candidate facility locations in the city of Jeddah, reducing the overall distance of travel from the districts to their closest health care facilities. In P-median allocation problem solutions, facilities are situated in such a manner that the amount of all weighted costs between the demand points and the solution facilities are reduced. The arrows in the accompanying diagram shown in Figure 1 illustrate the fact that the distribution is centred on the distance between all points of demand.

Mathematically, the P-median problem can be summarized as follows:

The objective function is to make $Z$ as small as possible:

Minimize $Z=\sum_{i \in I} \sum_{j \in J} a_{i} d_{i j} x_{i j}$

Subjective to possible constraints, an individual demand site must be assigned to a facility described as:

$\sum_{j \in \mathrm{J}} x_{i j}=1$ for all $i$

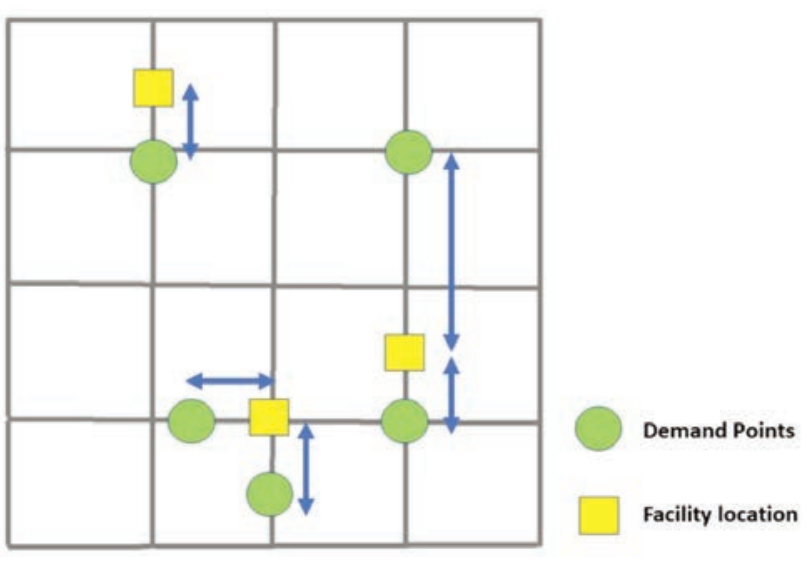

Figure 1. The P-median model process. 
Demand must be assigned to an open facility as follows:

$\mathrm{x}_{i j} \leq \sum_{x i j}$ for all $(i, j)$

The number of facilities $(p)$ must be located (the number of communities assigned to themselves equals the number of facilities to be located):

$\sum_{j \in J} x i j=p$

All demand from an individual demand site is assigned to only one facility:

$X_{i j}=(0,1)$ for all $(i, j)$

where $Z$ is the objective function; $I$ the set of demand areas (usually nodes of a network); the subscript $i$ an index denoting a particular demand area; $J$ the set of candidate facility sites (usually nodes of a network); the subscript $j$ an index denoting a particular facility site; $a_{i}$ the number of people from demand site $i ; d_{i j}$ the distance or time (travel cost) separating place $i$ from candidate facility site $j$. $d_{i j}=1$ if demand at place $i$ is assigned to a facility opened at site $j$ or $=0$ if demand at place $i$ is not assigned to that site. $p$ is the number of facilities to be located (Cromeley and McLafferty, 2011).

Road network coverage was used for the P-median model, and it was applied using health centres as $p$ and city population as $i$ (demand location).

\section{Results}

\section{Spatial distribution of health care centres}

Table 2 and Figures 2 and 3 show the results of a natural breaks classification of health centres based on patient number, which indicates that the city can be classified into three parts (A, B and C) according to health centre patients. Part A consists of health centres located in the central-eastern parts of the city (such as alSafa, al-Marwah and al-Naseem), which serve 94\% more patients than all other parts of the city; Part B shows patients living in the northern and western city districts (such as al-Shati and alMohammadiah), which have a low population density and thus a lower number of patients compared to Part A. Additionally this area has 5 public health centres, however people in here prefer private health centres over public health facilities. Part $\mathrm{C}$ displays north-eastern areas of the city in districts, which are not served by any public health centres, so the inhabitants use only private health centres.

Figure 4 shows a further classification of health centres based on doctors working in each centre. This graph shows that there is a larger supply of medical personnel at the eastern health centres to accommodate the higher health care demands at these locations.

\section{Access classification}

Figure 5 displays the zones from where people can access a health care centre in Jeddah within $15 \mathrm{~min}$. As can be seen about $60 \%$ of city districts fall outside the acceptable 15-min. travel radius. The next step was to identify the population size living in these zones. As seen in Figure 6 a remarkably large population live near health centres located in the eastern and middle parts of the city, while the number of people decreases near the northern and western health care centres.

\section{Location-allocation}

ArcGIS network analysis was used to produce the P-median location-allocation model for Jeddah health care centres (Figure 7). This output helped each health centre to its optimum location. For example, Azizia health centre was allocated for two districts (Azizia and Mushrifah) (Table 3). The Allocation function of ArcGIS produces a table output which defines the optimum health care centre allocations, including the name of the health centre and its assigned districts. This output can be used by health planners in Jeddah to select optimum health centre service areas.

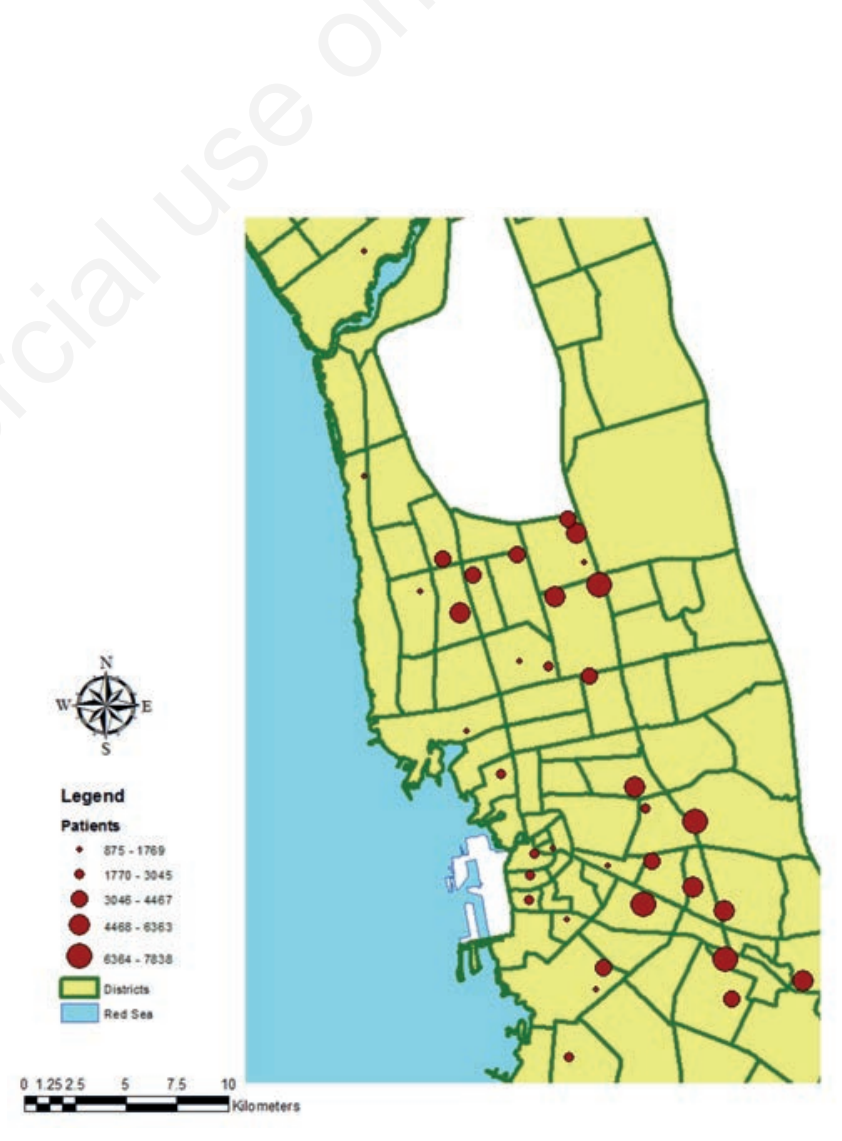

Figure 2. Location and size of health centres in Jeddah City. White areas in the map show the seaport and airport.

Table 2. City of Jeddah classification based on health centre demand.

\begin{tabular}{lcccc} 
Zone & Area $\left(\mathrm{km}^{2}\right)$ & Number of districts & Number of health centres \\
A & 268.186484 & 46 & 31 & Number of patients \\
B & 184.406593 & 21 & 5 & $1,242,69$ \\
C & 688.891789 & 43 & 0 & 71,89 \\
\hline
\end{tabular}




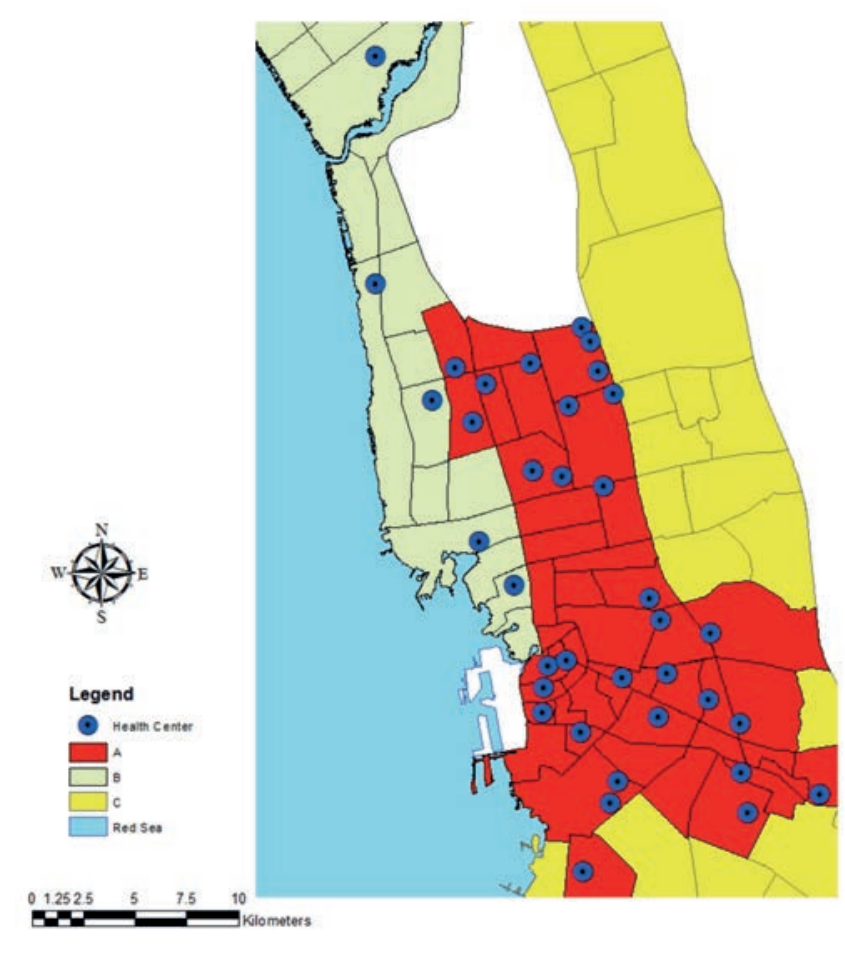

Figure 3. Classification of Jeddah based on health centre demand. $A=$ the areas with the highest population density, which are served by many health centres; $B=$ areas with a low population density; $C$ = areas not served by any public health centres.

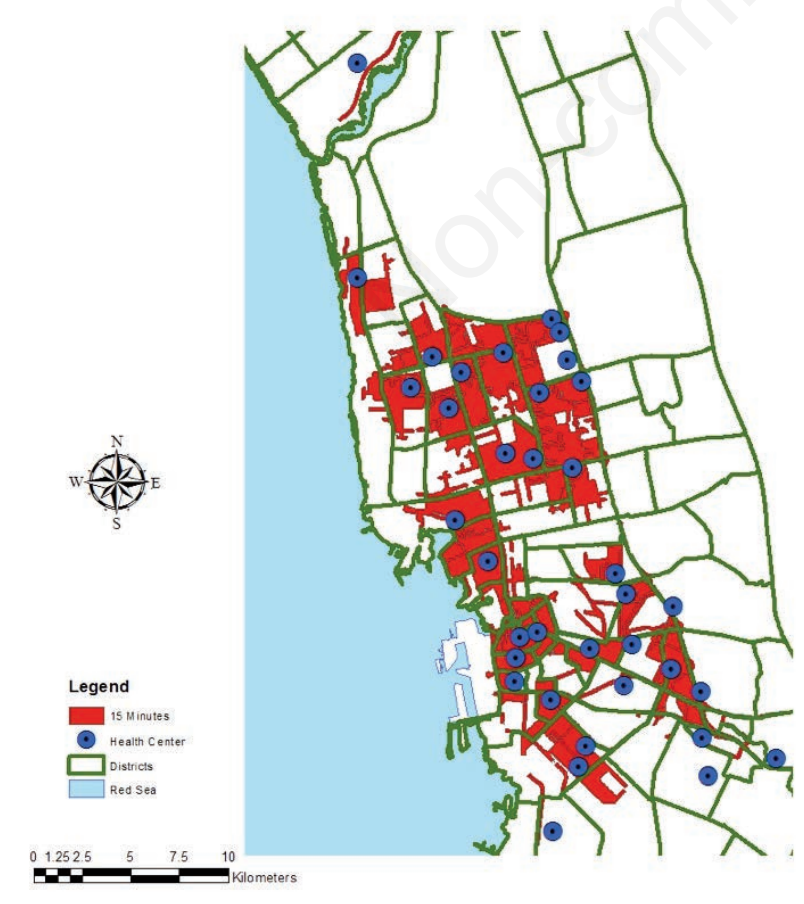

Figure 5. Areas in Jeddah from with health centres reachable within a $15-\mathrm{min}$. travel by car.

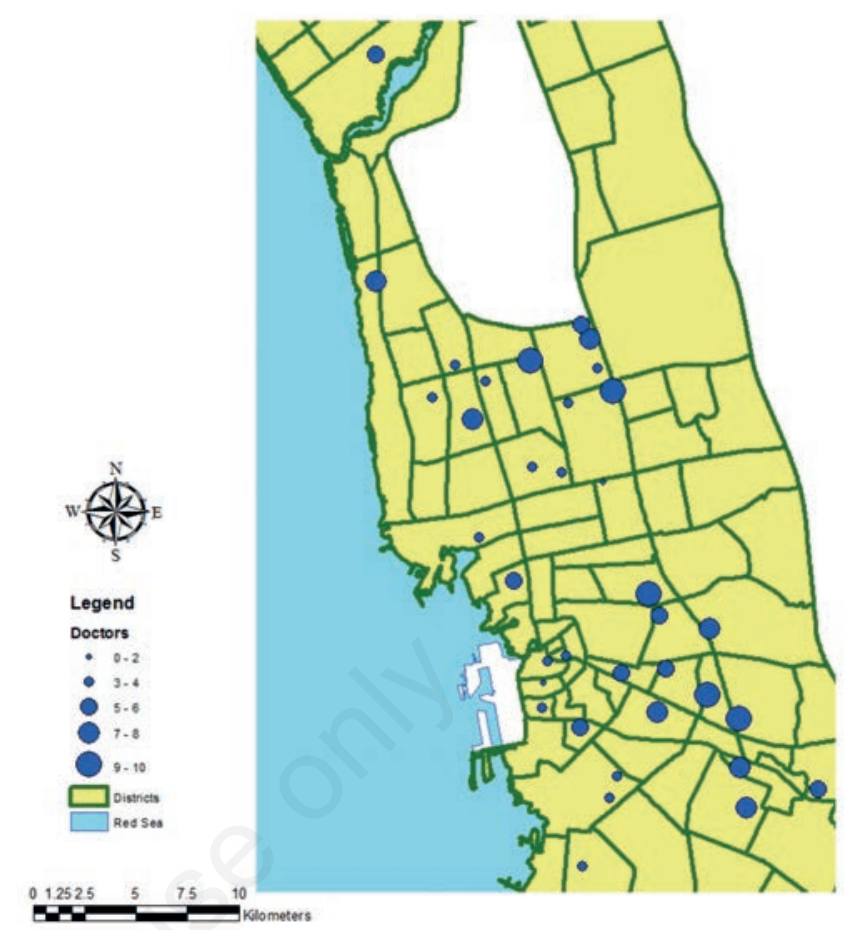

Figure 4. Classification of health centres based on the number of doctors available.

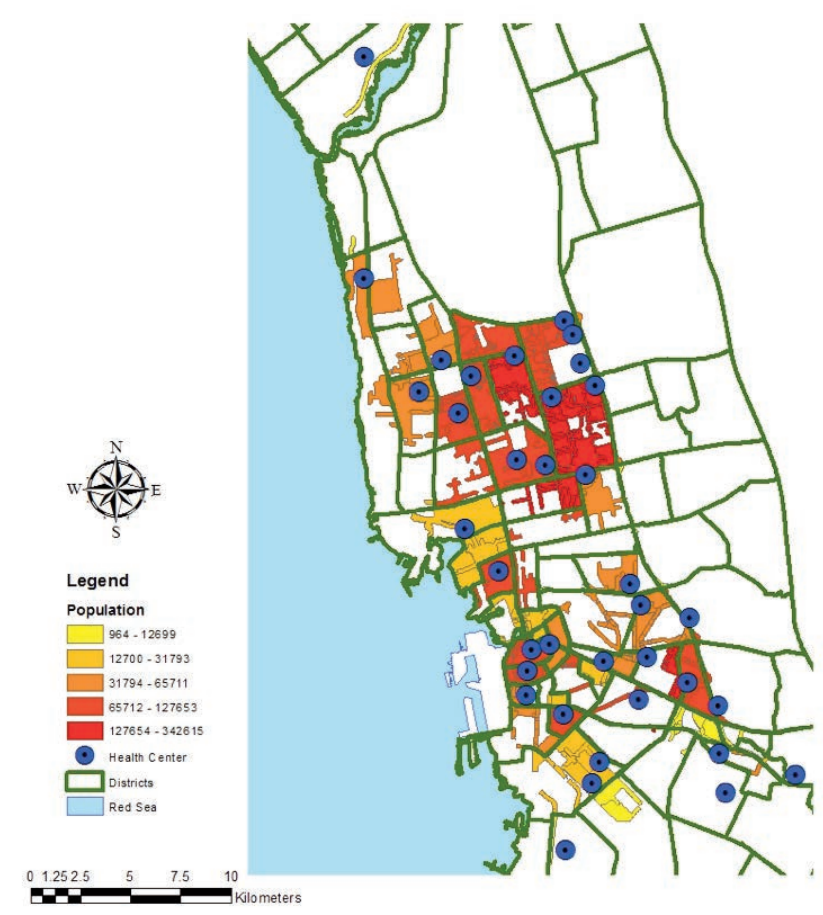

Figure 6. Number of people living near health centres in various parts of the city. 


\section{Discussion}

This paper has attempted to point out problem of health facility location, which entails allocating an optimal set of locations. Earlier studies have shown that spatial accessibility and variability are two important considerations for the essential service provision in an efficient fashion. Rahman and Smith (2000) found the Pmedian tool interesting because of its assumption that service users generally tend to travel short distances to avail services, which means less weight of travel duration is the most important issue for service users to reach their nearest facilities. In case of the AlAaaizia health centre, the output of the location-allocation P-median model (Figure 7) confirmed that this health, facility could provide services effectively to demand points located in the two districts Al-Aaaizia and Mushrifah. Dzator and Dzator (2013) found the P-median model highly suitable in the allocation of emergency services.

Mathematical modelling based on GIS can also describe the spread of communicable diseases and offer solutions based on optimisation (Elmes, 2004). However, we used the GIS-based optimisation model based on the P-median tool for allocating health care services to the optimum locations in Jeddah. The objective was to locate health care centres among a set of candidate facility sites (population districts) that would minimize the total travel distance to serve the population assigned to the health centre as discussed by Afshari and Peng (2014) and Tao et al. (2014) who they proposed optimal healthcare centres locations with a modified Pmedian model in Henan Province, China. However, the latter research team conducted their study in a context where multiple models of urban transit are available, while we used conventional P-median model because of the car-dominant nature of Jeddah City, where the impact of various transportation network types is absent. The results presented by this paper can be of great value for allocating health care services at optimum locations.

Another important use for GIS was in the preparation of maps of health care locations. These maps can be used to explain patterns of service areas, to provide residents with information on service locations and availability and to visualize the spatial match between service needs and resources (Murad, 2018). Information collected about the number of patients enables the calculation of feature classification and density, which assists the plotting of health centre spatial data. Exploratory spatial data analysis used numerical and visualization aspects to detect spatial data properties. It is necessary to connect numerical and graphical procedures to the map, so that the analyst can address the question: Where are these health centres on the map? GIS emphasizes the geographical dimensions of access, such as spatial accessibility. People's access to health services is rooted in their daily activity patterns in time and space. With the home as a base of activity, people move about in space to conduct various activities, which relates to work, school, shopping, and care of children or the elderly. These movements form a catchment area of activity, a geographically defined zone typically centred on the home, within which everyday life unfolds. Access to health care is an important component of the space of activity, which can be a constraining factor.
The role of geographic accessibility in service utilization depends on population characteristics. How well people overcome distance constraints depend on their capacity to use certain services. Travel for health care is strongly affected by demographic and socioeconomic characteristics, such as income, occupation, age and gender (Murad, 2014). Research shows that people whose mobility is limited by various reasons are more sensitive to distance, and thus more likely to use the nearest health care provider or even forgo care altogether. Although distance is a fundamental factor in geographical access, travel time, cost, transportation access and perceived distance are often of high relevance to health care utilization. Assisted by GIS, one can estimate travel time along road networks, considering average speeds and speed limits on different classes of roads and physical barriers to travel (Murad, 2014).

Modelling the optimum distribution of health care service areas is one of the most important issues associated with health care planning. Optimization is a statistical science that offers a way to balance dynamic relationships around a system in engineering and science, and there is a tradition of using optimization to support medical decision-making (Murad, 2005). Versions of locationallocation modelling are used to identify right sites for new facilities, including health services. For example, the choosing of a new site for a primary health centre or a diabetes centre would consider current sites for available health care, as well as the basic need for facilities (Khashoggi and Murad, 2020). These models look for a

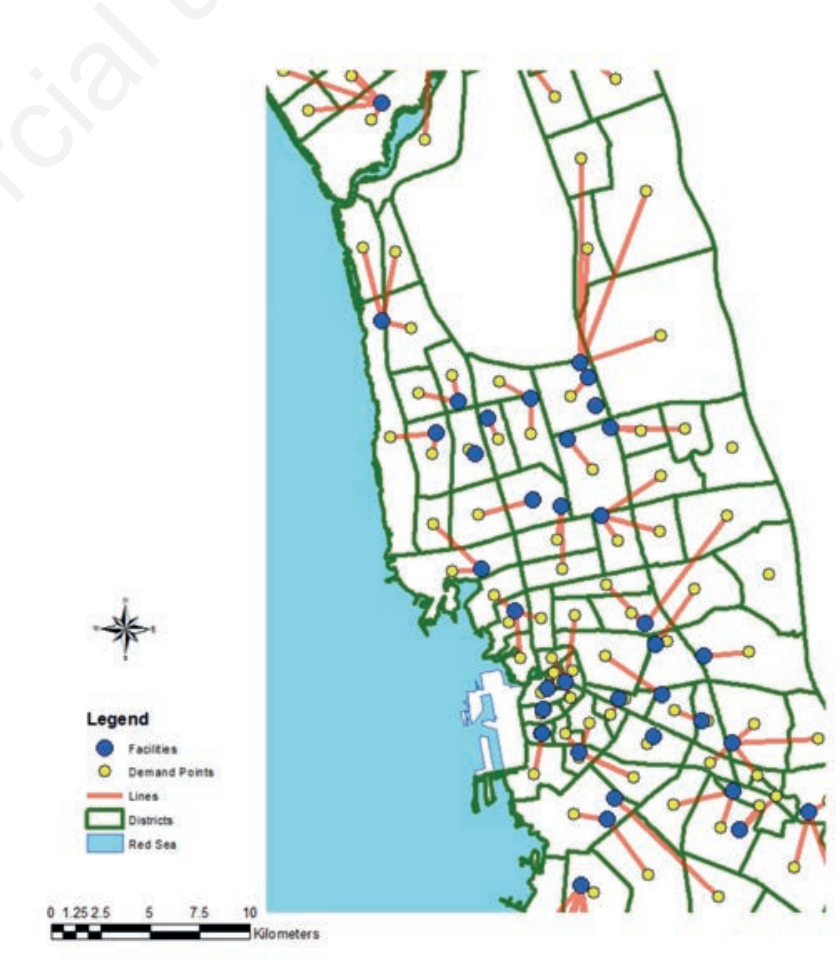

Figure 7. Location-allocation P-median model for health centres in the city of Jeddah.

Table 3. Allocation results for Azizia health care centre.

\begin{tabular}{|c|c|c|c|c|c|c|}
\hline Object ID & Name & Facility ID & Demand ID & Weight & Total weight & Total length \\
\hline 8 & Azizia-Azizia & 4 & 37 & 1 & 1814.337971 & 1814.337971 \\
\hline 9 & Azizia-Mushrifah & 4 & 38 & 1 & 3351.537048 & 3351.537048 \\
\hline
\end{tabular}


set of places from a set of candidate locations that optimize or decrease the objective function. Location-allocation models are represented in mathematical programming approaches that can be described as a set of numerical methods contributing to solving optimization problems associated with public health scenarios (Gong et al., 2017). Normative models of facility location or service delivery do not seek to describe existing facility locations. Instead, they are designed to identify the facility locations that maximize or minimize a mathematical function, which expresses the objective of the decision-maker.

The efficacy of our research can be understood when considering the emerging new urbanism paradigm, in which the 15-min. city is emphasised. Such consideration is inevitable when aiming to ensure sustainability in post-pandemic urban planning (Moreno et al., 2021). This type of city denotes a new kind of urban planning that re-links city dwellers by decentralizing urban facilities and urban life (Smith, 2021). Many global cities i.e. Paris, France (Euklidiadas, 2020) and Seattle, USA (Vansynghel, 2020) are seriously thinking of entering in the $15-\mathrm{min}$. city club. Currently, health facilities in Jeddah are located in certain parts of the city, while a large portion of the population would be isolated under the 15-min. norm of health care accessibility. Hence, the realignment of health facilities would only be possible by optimizing health centre locations and establishment of new health centres in line with the results of the proposed P-median model discussed here.

\section{Conclusions}

The results of the study offer an evidence base for urban planners and policymakers involved in the planning of health facilities that could be most beneficial for those concerned with planning of the health sector. It is in line with the new 15-min. city model, focused on maximising sustainability in post-pandemic urban planning. It suggests decentralisation of life and facilities, in which essential facilities and services, basic healthcare in particular, would be available by walking within $15 \mathrm{~min}$. or better.

\section{References}

Aljoufie M, Tiwari A,2021. Modelling road safety in car-dependent cities: case of Jeddah city, Saudi Arabia . Sustain-Basel 13:1816.

Aljoufie M, Tiwari A, 2020. Exploring housing and transportation affordability in Jeddah. House Policy Debate 2020 [Epub ahead of print].

Apparicio P, Jérémy G, Anne-Sophie D, Simon K, Lise G, Éric R, 2017. The approaches to measuring the potential spatial access to urban health services revisited: distance types and aggregation-error issues. Int J Health Geogr 16:32

Carson YM, Rajan B. 1990. Locating an ambulance on the Amherst campus of the State University of New York at Buffalo. Informs J App An 20:43-9.

Chotchoungchatchai S, Aniqa IM, Woranan W, Warisa P, Walaiporn P, Viroj T, 2020. Primary Health Care and Sustainable Development Goals. Bulletin of the WHO 98:792-800.

Dzator M, Dzator J, 2013. An effective heuristic for the P-median problem with application to ambulance location. OPSEARCH 50:60-74.

Elmes GA, 2004. GIS in public health care planning: the United States perspective. In: Maheshwaran R, Craglia M (Eds.), GIS in public health practice. CRC Press, New Delhi, India, 205 pp.
Euklidiadas MM, 2020. Paris wants to become a '15-Minute City'. Smart City Lab; 2020. Available from: https://www.smartcitylab.com/blog/governance-finance/paris-15-minute-city/ Accessed: 15 February 2021.

Gaans DV, Graeme H, Tonkin, A. 2016. The development of a spatial model of accessibility to phase 2 cardiac rehabilitation programs. J Spat Sci 61:217-31.

General Authority of Statistics, 2018. Data, Riyadh. Available from: https://www.stats.gov.sa/en/node Accessed: 15 February 2021.

General Authority of Statistics, 2019. Data, Riyadh. Available from: https://www.stats.gov.sa/en/node Accessed: 20 February 2021.

Gong H, Simwanda M, Murayama Y, 2017. An Internet-based GIS platform providing data for visualization and spatial analysis of urbanization in major Asian and African cities. ISPRS Int Geo-Inf 6:257.

Guagliardo MF, 2004. Spatial accessibility of primary care: concepts, methods and challenges. INT J Health Geogr 3:3.

Hamid A, Peng Q, 2014. Challenges and solutions for location of healthcare facilities. Ind Eng Man 3:2.

Khashoggi BF, Murad A, 2020. Issues of healthcare planning and GIS: a review. ISPRS Int Geo-Inf 9:352.

Kim Y, Byon YJ, Yeo H. 2018. Enhancing healthcare accessibility measurements using GIS: a case study in Seoul, Korea. PLoS One 13:e0193013.

Kistemann T, Queste A, 2016. GIS and communicable disease control. In: Craglia M, Maheswaran R (Eds.), GIS in public health practice. CRC Press, New York, NY, USA, 81 pp.

Lefebvre B, Chapelet P, 2005. Contextualizing the urban healthcare system. Methodology for developing a geodatabase of Delhi's healthcare system. Rajdhani Art Press, New Delhi, India.

Li Z, Serban N, Swann JL, 2015. An optimization framework for measuring spatial access over healthcare networks. BMC Health Serv Res 15:273.

Luo J, Tian L, Luo L, Yi H, Wang F, 2017. Two-step optimization for spatial accessibility improvement: a case study of health care planning in rural China. Bio Med Res Int 2017:12.

Macharia PM, Ouma PO, Gogo EG, Snow RW, Noor AM, 2017. Spatial accessibility to basic public health services in South Sudan. Geospat Health 12:510.

Maheshwaran R, Haining, RP. 2004. Basic issues in geographical analysis. In: Craglia M, Maheswaran R (Eds.), GIS in public health practice. CRC Press, New York, NY, USA, 13 pp.

McAleer WE, Naqvi IA, 1994. The relocation of ambulance stations: a successful case study. Eur J Oper Res 75:582-8.

Ministry of Health, 2020. Caring for our health, Saudi Vision 2030; Riyadh. Available from: https://www.vision 2030. gov.sa/en/node/68 Accessed: 25 February 2021.

Moreno C, Allam Z, Chabaud D, Gall C, Pratlong F, 2021. Introducing the '15-Minute City': sustainability, resilience and place identity in future post-pandemic cities. Smart Cities 4:93-111.

Murad A, 2005. Using GIS for planning public general hospitals at Jeddah City. JKAU Env Design Sci 3:3-22.

Murad A, 2018. Using GIS for determining variations in health access in Jeddah City, Saudi Arabia. ISPRS Int Geo-Inf 7:254.

Murad A, 2014. Using geographical information systems for defining the accessibility to health care facilities in Jeddah City, Saudi Arabia. Geospat Health 8:661.

Naji A, Almaimani A, Khan RR. 2020. Analysis of the current development of community centres in Jeddah City. Open House Int 45:249-68.

Papanikalaou BJ, 1950. World Health Organization. Tuberculosis 
surveys. V. Iran, Irak, Lebanon, Saudi Arabia, Syria and Transjordan. Tubercle 31:42-5.

Photis YN, 2016. Disease and health care geographies: mapping trends and patterns in a GIS. Health Sci J 10:1.

Rahman R, Al-Borie HM, 2020. Strengthening the Saudi Arabian healthcare system: role of vision 2030. Int J Healthcare MGT 3:1-9.

Rahman SU, Smith DK, 2000. Use of location-allocation models in health service development planning in developing nations. Eur J Oper 123:437-52.

Ríos-Mercado RZ, Álvarez-Socarrás AM, Castrillón A, LópezLocés MC, 2021. A location-allocation-improvement heuristic for districting with multiple-activity balancing constraints and p-median-based dispersion minimization. Comput Oper Res 126:105106.

Salehi F, Ahmadian L, 2017. The application of geographic information systems (GIS) in identifying the priority areas for maternal care and services. BMC Health Serv Res 17:482.

Serra D, Marianov V, 1998. The P-median problem in a changing network: the case of Barcelona. Lect Sci 6:383-94.

Smith G, 2021. Decentralization, healthcare and the 15-Minute
Cities. Available from: https://www.greshamsmith.com/blog/ 15-minute-city-healthcare/ Accessed: 22 Feb 2021.

Tao J, Tao H, Qin K, Wang Y, Liu C, Gao Q, 2014. Selecting the optimal healthcare centres with a modified P-median model: a visual analytic perspective. Int J Health Geogr 13:42.

Tomintz M, Clarke GP, Alfadhli N, 2015. Location-allocation models, in geocomputation: a practical primer. SAGE, London, UK, 185 pp.

Vansynghel M, 2020. Seattle could become the next 15-Minute City. Crosscut; 2020. Available from: https://crosscut.com/ focus/2020/11/seattle-could-become-next-15-minute-city Accessed: 22 February 2021.

Wang F, 2012. Measurement, optimization, and impact of health care accessibility: a methodological review. Ann Assoc Am Geogr 102:1104-12.

Wang F, 2020. Why public health needs GIS: a methodological overview. Ann GIS 26:1-12.

WHO, 2000. The World Health Report 2000. WHO, Geneva, Switzerland. Available from: https://www.who.int/whr/2000/ en/whr00_en.pdf?ua=1 Accessed: 22 February 2021. 